\title{
Elementos para a compreensão da estética do Taekwondo
}

\author{
Rebeca Cardozo Coelho* \\ Lev Kreft ${ }^{* *}$ \\ Teresa Lacerda ${ }^{* * *}$
}

\begin{abstract}
Resumo: Conhecimento com um vasto potencial ainda por explorar, a estética do desporto desperta cada vez mais interesse no campo científico. Este ensaio busca contribuir para a compreensão da experiência estética vivenciada pelo atleta de Taekwondo. Realça-se que esta experiência decorre do jogo do Taekwondo, no qual importa considerar o desafio, a disputa, de que decorre imprevisibilidade, gerando-se situações de risco. Este arriscar, deslizar na imaginação e na ação, conduz umas vezes ao prazer, outras ao desprazer, ambos configuradores da experiência estética.
\end{abstract}

Palavras-chave: Experiência Estética. Taekwondo. Jogo. Risco.

\section{INTRODUÇÃo}

A estética do desporto é uma área que tem merecido cada vez mais o interesse da investigação em Ciências do Desporto. Desde a década de 1970 tem-se procurado desenvolver e consolidar este domínio do conhecimento, sendo que o momento de inflexão introduzido por Best (1988) no contexto da especulação acerca das convergências e divergências entre o desporto e a arte, constituiu, em nosso entender, um impulso fundamental para o avanço da

\footnotetext{
"Estudante/Investigadora do Centro de Investigação, Formação, Inovação e Intervenção em Desporto (CIFI2D), na área do Desporto, Educação e Cultura, da Faculdade de Desporto, Universidade do Porto, Portugal. E-mail: rebecacoelho@hotmail.com

"Professor da Faculdade de Arte e da Faculdade de Desporto, Universidade de Ljubljana (UL), Eslovénia. E-mail: lev.kreft@guest.arnes.si

"'Professora do Centro de Investigação, Formação, Inovação e Intervenção em Desporto, Faculdade de Desporto, Universidade do Porto (UP), Portugal. E-mail: tlacerda@fade.up.pt
} 
investigação. A fim de justificar a aproximação do desporto à estética, Best (1988) deslocou o foco da argumentação para os aspectos constitutivos e estruturantes do desporto, a partir dos quais decorre o seu valor estético, ao invés de permanecer centrado nas qualidades comuns ao desporto e à arte. Este entendimento foi prosseguido por outros autores, designadamente Parry (1989), Wright (2003), Lacerda e Mumford (2010) e Kreft (2012). O nosso trabalho avança na esteira destas investigações, fundando-se no pressuposto de que à estética contemporânea cabe refletir criticamente sobre a arte, a cultura e a natureza. De fato, e como refere Goldman (2005), o conceito de estética ampliou-se, qualificando não apenas julgamentos e apreciações, mas também propriedades, atitudes e experiências, pelo que a sua aplicação deixou de se restringir exclusivamente à beleza e aos objetos de arte esteticamente agradáveis. Deste modo, e tendo em conta o carácter de fenómeno cultural global do desporto contemporâneo, a estética tem vindo a desenvolver e a reforçar o seu interesse pela atividade desportiva.

Se até aqui nos referimos à estética do desporto, domínio de estudo relativamente recente mas em franco crescimento, importa evidenciar que no que respeita à estética dos desportos ${ }^{1}$ a literatura é ainda escassa, sendo possível, contudo, mapear estudos que elegem como objeto o futebol (MODERNO, 1998), o surf (COELHO, 2004), o ténis (NOGUEIRA; LACERDA; CÔRTE-REAL, 2006), a natação (FERNANDES; LACERDA, 2010) e a dança (LACERDA; GONÇALVES, 2009).

Realça-se que, mesmo sendo amplamente identificadas e aceites pelo conhecimento contemporâneo as diversas dimensões que compõem o corpo-indivíduo, e mesmo sabendo-se que é a articulação entre estas dimensões que permite ao atleta realizar a sua performance, algumas delas continuam sendo pouco valorizadas e investigadas. Para Bento (2011), no contexto das Ciências do

\footnotetext{
'Esclarece-se que os autores concebem o desporto como a pluralidade dos desportos e é nesse sentido que distinguem a estética do desporto (que estuda o desporto, tomando o fenómeno numa macroperspectiva) da estética dos desportos (que se debruça sobre a especificidade de cada modalidade desportiva, falando-se duma microperspectiva).
} 
Desporto, a obrigatoriedade de edificar e demonstrar a cientificidade das nossas instituições e do respectivo objeto de estudo, ocasionou grandes avanços nas áreas biológicas e afins, relegando todavia para o esquecimento a ética e a estética. Contudo, é cada vez mais consensual que a estética faz parte integrante do desporto (WRIGHT, 2003, LACERDA; MUMFORD, 2010, HOPSICKER, 2011), constituindo-se numa das suas dimensões originais.

Deste modo, parece que o século XXI manifesta um interesse renovado pela abordagem estética ao desporto. A este propósito menciona-se, a título de exemplo, o tema do XIV Congresso de Ciências do Desporto e Educação Física dos Países de Língua Portuguesa, "Desporto: Cultura, Estética e Excelência", e o número especial do Journal of the Philosophy of Sport, inteiramente dedicado à estética do desporto, reunindo um conjunto de nove artigos originais da autoria de investigadores de diferentes partes do mundo, dentre os quais um brasileiro e uma portuguesa.

No quadro das temáticas que a estética do desporto congrega, destaca-se o estudo acerca da experiência estética, que se pode focalizar tanto na perspetiva do atleta quanto na do observador. Embora alguns trabalhos tenham já enfatizado a importância da experiência estética do desportista (KIRK, 1986; COELHO, 2004; FERNANDES; LACERDA, 2010), é justamente neste domínio que se verificam grandes lacunas na literatura. No presente estudo promove-se este âmbito de investigação, procurando-se contribuir para a compreensão da experiência estética dos atletas de Taekwondo.

No que se refere a pesquisas acerca da estética aliada às lutas (artes marciais), verifica-se que a investigação está ainda pouco desenvolvida. Evidenciam-se dois artigos sobre o assunto. O primeiro, de Edinborough (2011), argumenta que as artes marciais são uma forma de arte semelhante à pintura, dança e literatura, proporcionando formas específicas de experiência que desencadeiam prazer e estimulam a imaginação, tanto do praticante quanto do espectador. É na compreensão destas experiências que se focaliza o nosso interesse, negligenciando de forma deliberada, como foi já referido 
anteriormente, a aproximação à arte. Prosseguimos as linhas que têm orientado uma boa parte da investigação internacional assim como a que se tem vindo a desenvolver nos últimos anos em Portugal (e.g LACERDA, 2004; LACERDA, 2007; FERNANDES; LACERDA, 2010); essa produção tem refletido a necessidade de legitimar a estética do desporto a partir, justamente, do valor estético da atividade desportiva em si. No outro artigo, Wojciech e Kazimierz (2011) apresentam alguns modelos, valores, dimensões das artes marciais, e, dentre estes, o modelo estético, que afirmam contribuir para o ideal de harmonia, de força, de aptidão física, assim como ajuda a configurar um estilo de vida.

Já no que diz respeito especificamente ao Taekwondo, objeto deste estudo, é de acentuar que se apresenta como um desporto pouco estudado, principalmente no que se refere ao entendimento das questões subjetivas do indivíduo. Vale observar os danos físicos associados à performance, o que reflete a preocupação de pesquisadores que buscam identificar como a prática do Taekwondo (de competição) pode lesionar o atleta (PIETER; HEIJMANS, 2000), apontando para a prevalência da "concussão cerebral" (PIETER; ZEMPER, 1994). Com efeito, nos desportos de combate o atleta pode lesionar-se de modo por vezes irreversível, como foi retratado de forma tão tocante no filme "Menina de Ouro", de Clint Eastwood (GUMBRECHT, 2007).

O Taekwondo é um desporto olímpico desde 1980, quando a World Taekwondo Federation (WTF) se tornou uma Federação Desportiva reconhecida pelo Comitê Olímpico Internacional, mas sua primeira participação nos Jogos Olímpicos ocorre apenas no ano 2000, na Austrália (WORLD TAEKWONDO FEDERATION, 2013). Apesar de ser um desporto olímpico recente, estima-se que seja praticado por cerca de 70 milhões de indivíduos ao redor do mundo (RAMIREZ, 2011).

Desconhece-se qualquer investigação empírica sobre a experiência estética do atleta de Taekwondo, tendo sido identificado apenas um artigo no qual se discutem alguns aspetos estéticos da modalidade. Nesta publicação, Il-hyeok (2000) evidencia que o 
Taekwondo não é caracterizado apenas como um desporto de ataque e defesa, mas também pela tranquila beleza das formas e movimentos, nos quais se podem encontrar valores e significados. É através deste jogo que o corpo desse cumpre em beleza e sublimidade, é o tempo e o espaço de recriação do corpo enquanto objeto estético. Deste modo, as diversas habilidades técnicas que integram o ataque e a defesa, que são treinadas individualmente, em pares, ou contra um maior número de oponentes, tornam-se essenciais e constituem o jogo do Taekwondo ${ }^{2}$.

A partir da literatura consultada, evidencia-se a necessidade de promover conhecimento acerca da experiência estética vivenciada pelos atletas de Taekwondo. É a tarefa que se empreende no presente trabalho, em que se busca compreender a esfera do sensível no sujeito (o atleta), o seu sentimento de prazer ou desprazer (KANT, 2010) advindo da prática desportiva; prática que, em função das suas características particulares, permite ao indivíduo vivenciar o belo ou o feio, ou seja, experienciar em si o valor estético da sua performance. Convocando a expressão de Arnold (1985, p. 2), o propósito do estudo situa-se em considerar a experiência estética no Taekwondo a partir da perspetiva que "emerge do interior da atividade na qual o atleta está envolvido. Experienciar esteticamente o desporto significa fruir a harmonia, a elegância, a fluidez, a graça do desempenho, bem como gozar a emoção que decorre da tensão do desafio, da altercação, do desequilíbrio que faz sobressair a eloquência da performance, que sobreleva o seu valor estético e que conduz um dos oponentes à vitória ${ }^{3}$.

\footnotetext{
${ }^{2}$ Não sendo nossa intenção no presente trabalho enveredar pela já clássica discussão epistemológica acerca da relação desporto/jogo, é importante salientar que no Taekwondo a dimensão do jogo desempenha um papel fundamental. É no contexto do jogo que se manifesta o risco, por isso o Taekwondo revela ser também um desporto de risco, que coloca o atleta diante de situações inesperadas, de golpes potentes, de sensações de medo, sofrimento e tensão.

${ }^{3}$ Importa reiterar que se entende que o debate acerca do valor estético do desporto não pode deixar de considerar as suas dimensões matriciais e, no caso vertente, a díade vitória/derrota, não sendo, contudo, propósito do estudo elaborar acerca deste assunto. Ainda assim, sublinhase que o valor estético não decorre da vitória ou da derrota enquanto produto da atividade desportiva, mas sim da qualidade do processo que culmina no triunfo ou no insucesso. Deste modo, há obviamente que ter em conta o valor estético da derrota que transporta a perda positiva, assim como o défice de valor estético da vitória obtida através de um jogo mal jogado.
}

Movimento, Porto Alegre, v. 19, n. 03, p. 295-314, jul/set de 2013. 
O desenvolvimento deste trabalho, que procura ajudar a construir um conhecimento de certo modo inexplorado, parte da consideração das peculiaridades do objeto de estudo (o Taekwondo), da revisão da literatura sobre estética do desporto, assim como da experiência pessoal de um dos autores na modalidade. Argumentase acerca da experiência estética do atleta de Taekwondo a partir do conhecimento sobre a experiência estética dos atletas no desporto (ponto 2), analisa-se a importância do jogo, real e imaginado, para a compreensão desta experiência (ponto 3) e discute-se o papel do risco neste domínio (ponto 4). Estas questões são reforçadas na última parte do artigo (ponto 5).

\section{ExperiênCia Estética do AtLeta}

As formas e os movimentos do Taekwondo podem ser considerados semelhantes à dança tradicional coreana, o que se evidencia, por exemplo, quando um atleta eleva o pé acima da cabeça ou executa pontapés que requerem uma habilidade técnica de elevado nível. Estes elementos podem ser usados simultaneamente para ataque e defesa (IL-HYEOK, 2000) e expressam qualidades estéticas que contribuem para a aproximação à arte destacada por Il-hyeok (2000) e Edinborough (2011). Contudo, não é necessária nem exclusivamente desta conciliação com a arte que decorre o valor estético dos mais variados elementos técnicos do desporto; como é sublinhado por Arnold (1978) se, por um lado, não é legítimo estabelecer uma relação direta entre habilidade técnica e valor estético, por outro, é inegável que com muita frequência se estabelece essa relação. Em nosso entender, a estética é um valor interno do desporto, que decorre dos atributos intrínsecos de cada modalidade desportiva (entre aos quais se inclui, evidentemente, a técnica). Neste sentido, evidenciam-se qualidades estéticas no poomsae (sequência de movimentos pré-determinados de ataque e de defesa elaborados por grandes mestres) e no combate, quando se sobrelevam aspetos determinantes para o desempenho técnico como a concentração, o controlo corporal, o equilíbrio, a unidade, o contraste, o ritmo, a 
velocidade, a amplitude, a agressividade, a suavidade, a precisão na execução dos movimentos, que permitem ao atleta manifestar um estilo próprio, na busca pelos golpes perfeitos. A proficiência técnica abre ao atleta a possibilidade de interpretar de forma singular cada habilidade técnica, de lhe conferir a sua marca pessoal, distintiva, libertando-o para encontrar e definir um estilo próprio.

Vale a pena salientar que o combate, por não ser uma sequência de movimentos pré-definidos (como o poomsae, ou como um exercício de ginástica rítmica ou de patinagem artística), exige do praticante uma grande capacidade de improvisação, constante readaptação e antecipação, na procura em explorar as fraquezas do oponente e dialogar com as próprias, num estado de prontidão para o ataque e para a defesa. Trata-se de algo semelhante ao que Moderno (1998, p. 57) evidencia a propósito do jogador de futebol que "joga inventando o modo de jogar". Este aspecto, ao contrário de depreciar, antes exponencia a estética do confronto. $\mathrm{O}$ combate requer combinação indeterminada de ações e de interações, reação quase instantânea às dificuldades colocadas pelo opositor e às adversidades da luta. Um pouco à semelhança do que se passa nos jogos desportivos colectivos, em que estes aspectos contribuem para amplificar a sua estética (LACERDA, 2007), também nos desportos de combate como o Taekwondo, aquelas características se conjugam para a configuração do seu valor estético.

Il-hyeok (2000) assinala que a perseverança manifestada pelo atleta que executa os movimentos com todas estas características de embelezamento, permite ao observador vivenciar também uma experiência estética. A apreciação da beleza das expressões exteriores dos movimentos advém dos sentimentos interiores do atleta, sentimentos estes que são subjetivos, mas também interativos e que, portanto, comunicam com o observador. Convém, contudo, distinguir claramente que a experiência estética do atleta deriva do facto de ser o autor das suas próprias ações, enquanto a experiência estética do espectador resulta da interpretação que faz da performance que presencia (ARNOLD, 1985). 
Como se descreve a natureza da experiência estética vivenciada pelo atleta ao realizar os diversos movimentos? Existem várias tentativas para caracterizar a experiência estética, ou algo intimamente relacionado com este tipo de experiência, como o prazer estético ou a admiração (STECKER, 2006). A experiência estética é mais magnificente do que uma experiência simplesmente. No desporto o atleta busca compreender as formas, qualidades e significados dos seus movimentos e suas inter-relações, experienciar (sentindo e pensando) o modo como todos estes aspetos emergem a partir de um conjunto específico de características. Para tal, é necessário que adote uma atitude subjetiva, uma pré-disposição específica, um tipo particular de atenção, a que corresponde um modo singular de perceção das atividades desportivas (LACERDA, 2004). A experiência estética caracteriza-se pelo conteúdo do fenómeno da cognição que se apresenta na nossa perceção, assim como pelo seu carácter singular, pois cada indivíduo sente o prazer estético onde o encontra e a variedade dos gostos pode se abrir num leque multiforme (HUISMAN, 2008; KANT, 2010).

Diante do que foi dito, evidencia-se que o atleta de Taekwondo pode experienciar o prazer estético em vários momentos distintos durante a sua prática, dependendo do estado emocional naquele exato momento e também da forma como se envolve, interessada (no sentido prático-utilitário) ou desinteressada (no sentido estético), libertando ou contendo os movimentos do seu corpo num fluir que estrutura o desenho da sua performance.

Iseminger (2003) refere que o grau de complexidade, de intensidade e de unidade do prazer estético, da experiência estética, embora diretamente relacionado com a complexidade, intensidade e unidade do objeto em causa, não é redutível a ele: trata-se de uma característica da própria experiência. Deste modo, o valor estético do objeto reside na sua capacidade em produzir experiências deste tipo, sendo estas experiências, por sua vez, valiosas de diversas maneiras para aqueles que as têm, por exemplo, na integração do eu, no refinamento da perceção e no desenvolvimento da imaginação. 
Neste seguimento, Mitias (1986) considera que a experiência estética não existe apenas na sensibilidade do indivíduo, mas também na imaginação (SCHILLER, 1991; KANT, 2010), pelo que o artista pode saborear o gozo das qualidades estéticas que consegue criar durante a produção da sua pintura, ou, no caso vertente, o gozo das qualidades estéticas que o atleta consegue criar na prática desportiva.

O Taekwondo é um jogo que permite no combate a interação entre os atletas (e aqui destaca-se o contacto físico, o corpo a corpo), e no poomsae a interação entre o atleta e a sua imaginação. Apresenta também todas as características para permitir ao homem ser livre e reflexivo através do lúdico, da beleza e do prazer que configuram a experiência estética (MITIAS, 1986; SCHILLER, 1991; ISEMINGER, 2003; HUISMAN, 2008; KANT, 2010). O atleta de Taekwondo ao vivenciar esse livre jogo da sua própria natureza interior com a natureza imprevisível do adversário, encontra o seu estado de liberdade, vivendo a experiência de um homem em sentido pleno, o que nos conduz naturalmente a Schiller (1991) e à sua asserção de que o homem, diante do belo, joga, ampliando a satisfação do seu impulso lúdico.

\section{JOGO REAL E IMAGINADO DE COMBATER}

Se Schiller nos guia até ao jogo pela via da beleza, a incursão no jogo convoca a presença de Huizinga (1972). O autor afirma que o homem quando joga obedece a um impulso para satisfazer uma necessidade de relaxamento, para ganhar o domínio de si mesmo, ou pela necessidade de poder fazer algo. Para Huizinga (1972), a beleza do corpo humano em movimento encontra a sua expressão mais elevada num jogo, pois as suas formas mais desenvolvidas são ricas em alegria, graça, ritmo e harmonia, salientando-se a afinidade do jogo com a beleza. Esta relação (de atração) entre a estética e o jogo foi também desenvolvida por Schiller (1991, p. 92), que afirmou que o homem "somente é homem pleno quando joga". 
Huizinga (1972) e Caillois (1990) discorreram e elaboraram sobre as regras do jogo, considerando-o como uma ação e ocupação livre, que se desenvolve dentro de limites temporais e espaciais determinados. Para Caillois (1990), o jogo é uma fantasia agradável, uma distração. Designa não apenas uma atividade específica, mas também a totalidade das imagens, símbolos ou instrumentos necessários à sua prática, evidenciando-se, portanto, num conjunto complexo.

No jogo desportivo, a cada ataque ou defesa, o atleta estimula e confirma as suas capacidades, específicas do sistema complexo constituinte de cada modalidade desportiva. Através da persistência, da tenacidade e do prazer daí decorrente, o participante consegue trazer para o nível da facilidade (ainda que aparente) o que antes poderia ser difícil e extenuante. Neste processo inclui-se o aprender a interagir com aquele que se ataca ou do qual se defende, o que é fundamental no Taekwondo, em que o atleta precisa aprender a lidar com o adversário, saber observá-lo e ganhar confiança, para só então o combater e vencer.

Caillois (1990) propõe a divisão do jogo em agon, alea, mimicry e ilinx. Na categoria agon predomina o papel da competição, na alea o da sorte, na mimicry o simulacro e na ilinx a vertigem. Ao partir desta compreensão do jogo, Gumbrecht (2007) afirma que o desporto perpassa pelo entendimento de agon e arete. Relativamente ao agon assinala que talvez seja mais bem traduzido simplesmente por competição, sendo que a competição está associada a uma domesticação de confrontos e tensões potencialmente violentos, balizados por parâmetros institucionais de regras estáveis. No que diz respeito à arete, declara que "significa buscar a excelência com a consequência (mais que com o objetivo) de levar algum tipo de performance a seus limites individuais e coletivos" (GUMBRECHT, 2007, p. 56). Embora possa parecer paradoxal falar em limites quando se evoca a arete, o que Gumbrencht (2007) pretende significar é que para se atingir esta excelência é necessário que o atleta se depare com a dificuldade, com oponentes exigentes, com qualidades 
equiparadas ou até mesmo superiores às suas. Triunfar diante de um adversário como este, requer um grande conhecimento de si mesmo, das suas limitações e potencialidades, impõe a necessidade de alcançar ou de se aproximar da excelência. Esta situação irá permitir ao atleta testar os seus limites e, eventualmente, transcenderse. Para Gumbrecht (2007), agon e arete conciliam-se na maioria dos eventos desportivos e convergem no impulso desportivo de ir além, de buscar o que nenhum outro foi capaz de alcançar antes.

Desta forma, e tendo em consideração o referencial citado, localizamos o Taekwondo: na categoria agon, pela sua vertente competitiva; na categoria alea, dado que incorpora a imprevisibilidade; na categoria mimicry, ao ativar a imaginação do atleta no combate real e na realização do poomsae (ao lutar contra um adversário imaginado); na categoria ilinx, por implicar o indivíduo na realização de movimentos muito exigentes física e tecnicamente, como por exemplo na execução dos pontapés rotativos e em suspensão. Tratase ainda de um desporto em que a demanda pela arete igualmente se impõe, na busca constante pela excelência. Em todos estes aspetos se funda a experiência estética do atleta, e cada um deles contribui em certa medida para a sua compreensão $0^{4}$.

O jogo desencadeia consequências imprevisíveis no prazer do desafio ou simplesmente da dificuldade ultrapassada, no prazer de ter medo, na vertigem, na busca da repetição e da perfeição, na alegria de improvisar, de criar, de variar as soluções até ao infinito e no desejo de se prestar com astúcia a uma prova de força, de habilidade, de velocidade, de resistência, de equilíbrio, de flexibilidade.

O desejo do atleta em vencer um adversário durante um combate, transforma-se num jogo de superação de si mesmo, no qual a imaginação criadora se encontra presente. $\mathrm{O}$ adversário exibe características da mimicry, num jogo dramático, seduzindo o atleta a explorar os seus sonhos, desejos e desafios, constituindo-se como

${ }^{4} \mathrm{~A}$ importância destes aspectos não se circunscreve unicamente à experiência do atleta. Para Masterson (1983) quando a excelência é atingida no desporto, o público reconhece-a e descrevea como bela. Relativamente à imaginação, Aspin, (1983) evidencia que é uma qualidade fortemente apreciada por praticantes e espectadores. 
objetivo maior acertar o oponente no local correto, para então pontuar e vencê-lo - a táctica, plena de dissimulação, finta, disfarce, é aqui fundamental e contribui para a expressão do valor estético da performance.

Este jogo de máscaras (no sentido teatral, de representação), imaginado, é muito evidente também quando o atleta está realizando um poomsae, tendo que buscar, a partir dos movimentos técnicos pré-organizados, a harmonia intelectual e física que lhe permite converter a tensão dramática em facilidade, expressividade e graça, de modo a vencer os seus adversários.

O prazer de superar o opositor no jogo, real ou imaginado, que se representa no Taekwondo, ajuda a compreender a experiência estética do atleta, homem destemido e audaz que, através da experiência lúdica, acede à experiência estética, sendo também capaz de se realizar pelo risco implicado no jogo.

\section{Risco de Combater}

Na prática de atividades de risco ${ }^{5}$, como o Taekwondo, o praticante ao tentar ultrapassar os seus limites pode enfrentar o medo, a possibilidade de lesões, das mais simples e fáceis de curar, às lesões mais graves. Ao entrar num combate contra um adversário, o atleta coloca-se diante do desconhecido, vivendo uma situação de grande tensão. É necessário considerar, como alerta Coelho Filho (2007), que o movimento do corpo performático pode ser perigoso e arrastar o atleta para a hýbris, o descomedimento, fazendo-o ultrapassar o métron, que é a medida de cada um, o limite próprio do ser humano.

Em termos simbólicos, parece-nos interessante evocar o pensamento de Ferguson (2004), que evidencia que na zona de combate, durante uma guerra, o medo não é apenas um sentimento

\footnotetext{
${ }^{5}$ Embora o espaço deste artigo não permita maior desenvolvimento, esclarece-se que os autores não circunscrevem o risco no desporto aos desportos de combate. A ginástica artística, as corridas de esqui ou os saltos para a água podem ser referidos, a título de exemplo, como modalidades em que a presença do risco é tão manifesta como no Taekwondo, ainda que sob outras formas.
}

Movimento, Porto Alegre, v. 19, n. 03, p. 295-314, jul/set de 2013. 
passageiro ou uma disposição psicológica, é um permanente estado do ser, é algo corpóreo, na verdade é o modo de corporificação específica para o combate, que se pode identificar, de forma semelhante, no Taekwondo. Trata-se de um estado de prontidão permanente, de pensar, sentir e agir com vista à melhor realização e à máxima satisfação. No valor estético da performance reconhecese a capacidade do atleta dar o seu melhor no momento decisivo, fazendo uso dos recursos estratégicos que lhe permitem resolver os conflitos táticos dos corpos no espaço, representando um drama. A ação de jogar é sempre dramática, porque o atleta nunca sabe o que vai acontecer. Mas, e à semelhança do que Kreft (2010) enuncia a propósito dos jogos desportivos coletivos, o drama não está relacionado apenas com o resultado final, pois pertence também ao prazer estético envolvido no jogo, aos elementos que proporcionam a alegria de jogar um jogo em si, jogo esse que incorpora risco para a integridade física, como sucede no Taekwondo.

Gumbrecht (2007) argumenta acerca do poder de atracão do boxe, igualmente um desporto de combate. Ao elaborar acerca da vitória de um atleta com vantagem estreita, desgastante física e mentalmente, conclui que se trata de sofrer, para então, se possível, voltar a reorganizar-se e assumir um domínio decisivo. Viver esta situação, de uma vitória bastante sofrida é, frequentemente, dos maiores triunfos a que um atleta pode aceder, que permanece registada para sempre na sua memória e que constitui, como nas situações de êxtase estético, uma situação regrante. Deste modo, e embora o significado do que foi vivido possa não ter sido verdadeiramente alcançado pelo atleta no momento, o reviver essa experiência, transformando-a numa "presença sempre disponível" (PERNIOLA, 1998, p. 18), vai permitir um entendimento que se mescla com o prazer estético.

No caso do Taekwondo, mesmo com o uso de proteções por todo o corpo, o rosto do atleta está permanentemente exposto e acaba por se tornar o alvo principal de todos os lutadores. A vontade e o desejo de atingir o adversário com um belo golpe certeiro no rosto é muito grande, pois os pontapés no rosto recebem maior 
pontuação, mas também são, na maior parte das vezes, os mais propícios de provocar a incapacidade do atleta continuar lutando, ou seja, de sofrer um nocaute. Esta situação de nocaute pode ser branda e fazer com que o atleta logo se levante e retome a luta, encarando novamente o seu adversário, mas pode também ser um pouco mais dramática. Mesmo não sendo um golpe que o impossibilite de prosseguir (já que pode estar restabelecido fisicamente), ainda assim o atleta pode desistir da luta, por ter medo e insegurança. Mas o golpe também pode ter sido traiçoeiro, pode ter sido um pontapé direto no pescoço, fazendo com que o atleta fique totalmente descomposto, tenha desmaiado ou mesmo sofrido uma grave lesão, vivenciando uma situação de alto risco.

Estas circunstâncias conduzem a que os atletas possam parecer loucos ao homem sensato, que não entende de onde vem o prazer dos indivíduos se agredirem fisicamente e colocarem a sua integridade em causa. $\mathrm{O}$ homem sensato tem necessidade de segurança, de equilíbrio e de controlo sobre as suas práticas, enquanto que para o homem aventureiro a incerteza e o desconhecido provocam-no, pois as emoções advindas dessas práticas explodem do risco (COSTA, 2000). Desta forma, identificamos no Taekwondo que o confronto do combate coloca o atleta diante de um jogo imprevisível, incerto e desconhecido. É preciso saber controlar a distância exata para o seu adversário e tentar esconder as suas ações táticas e técnicas, pelo que um erro pode ser fatal, pode ser suficiente para se expor, ficar vulnerável e viver uma situação de risco como um golpe certeiro na cabeça ou no abdómen, fazendo com que o oponente ganhe pontos ou o próprio combate, no caso de ocorrer um nocaute. Este jogo incerto, em que num minuto o atleta está na frente do placar e no outro minuto tudo pode mudar em função de um pontapé, faz com que o combate seja aliciante, emocionante e dramático.

No conceito bipolar de beleza descrito por Keenan (1975, p. 40), o valor estético da tragédia requer dor: "Quando o desprazer é percebido como um meio de fomentar o desenvolvimento e cultivar uma experiência, pode ser visto como estético e agradável, deleitável". Esta ideia remete para o argumento da perda positiva. Com efeito, 
no Taekwondo, os atletas conhecem as peculiaridades deste desporto e os riscos que correm, de se machucarem, sofrerem lesões, terem dor, momentos de sofrimento e de medo. O confronto com estas situações de desprazer não se esgota na perda, mas contribui para o fortalecimento e engrandecimento do atleta, podendo converter-se, portanto, num 'desprazer prazeroso'. Os atletas de Taekwondo estão conscientes da necessidade de serem combativos, demonstrando audácia para ultrapassarem os riscos e os seus próprios limites.

Atualmente a omnipresença do risco no Taekwondo é fortalecida pelo uso de coletes eletrônicos, em função da necessidade de se colocar uma certa potência no pontapé para que o ponto seja computado. Neste sentido, um pontapé rotativo e suspenso, preciso e forte, que cumpra as exigências biomecânicas, pode ser um movimento há muito desejado por um atleta e digno do sentimento de satisfação e prazer, não pela dor que causou ao seu oponente, mas pela sua concretização. A consequência deste belo golpe resultará certamente num sentimento contrário para quem o recebeu, de desprazer, de dor advinda do ataque, que pode ter machucado e provocado uma lesão, sem implicar no entanto uma leitura exclusivamente desfavorável em termos estéticos, como foi evidenciado anteriormente.

\section{Considerações Finals}

Ao longo deste trabalho procurou mostrar-se que a experiência estética do atleta concorre para o entendimento do desporto em análise, o Taekwondo. Destacou-se que o conhecimento e a compreensão dessa experiência promovem uma aproximação mais completa ao "eu-desportista" e ao desporto. A experiência estética do atleta resulta do jogo do Taekwondo, no qual o desportista tem que calcular, prever e decidir o momento certo, a distância precisa e a relação/combinação dos movimentos do seu corpo face ao adversário, real ou imaginado, o que envolve muito frequentemente situações de risco. $\mathrm{O}$ ato de arriscar, fluindo entre a imaginação e a ação, conduz por vezes ao prazer, outras vezes ao desprazer, ambos 
configuradores da experiência estética. Deste modo, a compreensão da experiência estética do atleta de Taekwondo contribui para a produção de conhecimento acerca do ato de combater presente em diversos desportos, assim como para o entendimento da experiência estética vivenciada pelos atletas no desporto em geral.

Por meio da abordagem estética, o presente trabalho procurou ajudar a clarificar uma outra dimensão deste fenómeno plural que é o desporto, estando o seu propósito inteiramente cumprido se as problemáticas aqui desenvolvidas se vierem a constituir em questões instigadoras para aqueles que buscam aprofundar o conhecimento acerca do fenómeno desportivo e, em especial, acerca dos desportos de combate. Promover a consolidação da estética do desporto por meio do estudo dos factores que pertencem inequivocamente ao universo desportivo, assim como de quem com eles interage, parecenos a via mais segura e profícua para o avanço do conhecimento. 


Elements for understanding the aesthetics of
Taekwondo
Abstract: A Knowledge with a vast unexploited
potential, the aesthetics of sport arouses increasing
interest in the scientific field. This essay seeks to
contribute to the understanding of aesthetic experience
experienced by the Taekwondo athlete. It is
emphasized that this experience stems of the
Taekwondo game, in which it must be considers the
challenge, the dispute, which stems from
unpredictability, generating risk situations. This risk,
slip on imagination and action, leads sometimes to
pleasure, sometimes to the displeasure, both
configurators of aesthetic experience.
Key words: Aesthetic Experience. Taekwondo. Game.
Risk.

Elementos para la comprensión de la estética
del Taekwondo
Resumen: Conocimiento con un vasto potencial sin
explotar, la estética del deporte despierta un creciente
interés en el campo científico. Este ensayo pretende
contribuir a la comprensión de la experiencia estética
experimentado por el atleta de Taekwondo. Subraye
que este experimento se deriva del juego de
Taekwondo, donde es importante razonar el desafío,
la disputa, que compone lo impredecible, lo que genera
situaciones de riesgo. Este riesgo, deslizar sobre la
imaginación y la acción, a veces lleva al placer, a
veces al desagrado, los dos configuradores de la
experiencia estética.
Palabras clave: Experiencia Estética. Taekwondo.
Juego. Riesgo.

\section{REFERÊNCIAS}

ARNOLD, Peter. Aesthetic Aspects of Sport. International Review for the Sociology of Sport, Warsaw, PL, n. 13, p. 45-63, 1978.

ARNOLD, Peter. Aesthetic Aspects of Being in Sport: The performer's Perspective in Contrast to that of the Spectateur. Journal of the Philosophy of Sport, Champaing, v. 12, p. 17, 1985.

ASPIN, David. Creativity in sport, movement and physical education. In: LENK, Hans (ed.). Topical problems of sport philosophy. Schorndorf: Karl Hofmann, 1983. p. 185-202. 
BENTO, Jorge Olímpio. Pedagogia do Desporto: Reencontros inadiáveis. In: SEMINÁRIO INTERNACIONAL DE FILOSOFIA, PESSOA E ESPORTE: OLIMPISMO, VALORES E DESENVOLVIMENTO HUMANO, 3, Brasil, 2011. [Anais...]

BEST, David. Sport is not art. In: MORGAN, William; MEIER, Klaus (ed.). Philosophic inquiry in sport. Champaign, Illinois: Human Kinetics, 1988. p. 527-539.

CAILLOIS, Roger. Os jogos e os homens. Lisboa: Edições Cotovia, 1990.

COELHO, Rebeca Cardozo. A estética do surf. In: CONGRESSO DE CIÊNCIAS DO DESPORTO E DE EDUCAÇÃO FÍSICA DOS PAÍSES DE LÍNGUAPORTUGUESA, Porto, 2004. Os desafios da renovação: 15 anos de congresso. Anais...

COELHO FILHO, Carlos Alberto de Andrade. Metamorfose de um corpo andarilho: busca e reencontro do algo melhor. São Paulo: Casa do Psicólogo, 2007.

COSTA, Vera Lucia de Menezes. Esportes de aventura e risco na montanha: um mergulho no imaginário social. São Paulo: Manole, 2000.

EDINBOROUGH, Campbell. Self-reflection and the Organization of Experience: Examining Inaba Minoru s Budo as a Form of Art. Journal of Asian Martial Arts, v. 20, n. 1, 2011.

FERGUSON, Harvie. The Sublime and the Subliminal: Modern Identities and the Aesthetics of Combat. Theory, Culture \& Society, London, v. 21, n. 3,p. 1-33, 2004.

FERNANDES, Rita Lopes; LACERDA, Teresa. A Experiência Estética do Nadador. Um estudo a partir da perspectiva de atletas de natação de alto rendimento. Revista Portuguesa de Ciências do Desporto, Porto, v. 10, n. 1,p. 180-188, 2010.

GOLDMAN, Alan. The Aesthetic. In: GAUT, Berys; LOPES, Dominic Mclver (ed.). The Routledge Companion to Aesthetics. London and New York: Routledge, 2005. p. 255-266.

GUMBRECHT, Hans Ulrich. Elogio da beleza atlética. São Paulo: Companhia das Letras, 2007.

HOPSICKER, Peter. In Search of the 'Sporting Genius': Exploring the Benchmarks to Creative Behavior in Sporting Activity. Journal of the Philosophy of Sport, Champaing, v. 38, p. 113-127, 2011.

HUISMAN, Denis. A estética. Lisboa: Edições 70, 2008.

HUIZINGA, Johan. Homo ludens. Madrid: Alianza, 1972.

IL-HYEOK, Lim. Taekwondo's Philosophy and Aesthetics. Koreana, Seoul v. 14, n. 4, p. 8-15, 2000. 
ISEMINGER, Gary. Aesthetic Experience. In: LEVINSON, Jerrold. The Oxford Handbook of Aesthetics. Oxford: Oxford University, 2003. p. 99-116.

KANT, Immanuel. Crítica da faculdade do juízo. Rio de Janeiro: Forense Universitária, 2010.

KEENAN, Francis. The Athletic Contest as a "Tragic" Form of Art. International Review for the Sociology of Sport, Warsaw, PL, v. 10, n. 39, p. 39-54, 1975.

KIRK, David. The aesthetic experience in sport. Journal of Human Movement Studies, London, n. 12, p. 99-111, 1986.

KREFT, Lev. Aesthetics of Football: keynote speaker. In: IFI Annual Symposium 2010, Sport: Artistic Representation, Aesthetic Appreciation. Preston: National Football Museum, 2010.

Sport as a drama. Journal of the Philosophy of Sport, Champaing, v. 39, n. 2, p. 219-234, 2012.

LACERDA, Teresa de Oliveira. Acerca da natureza da experiência estética desencadeada pelo encontro com o Desporto e do seu contributo para a educação estética do ser humano. In: LEBRE, Eunice; BENTO, Jorge (Ed.). Professor de Educação Física: ofícios da profissão. Porto: FCDEF-UP, 2004. p.301-307.

. A magia dos jogos desportivos e a estética do desporto. In: CONGRESSO INTERNACIONAL DE JOGOS DESPORTIVOS, 1., 2007. Olhares e Contextos da Performance. da Iniciação ao Rendimento. Porto: FADEUP, 2007. $1 \mathrm{~cd}$.

LACERDA, Teresa de Oliveira; GONÇALVES, Elsa. Educação estética, dança e desporto na escola. Revista Portuguesa de Ciências do Desporto, Porto, v. 9, n. 1, p. 105-114, 2009.

LACERDA, Teresa de Oliveira; MUMFORD, Stephen. The Genius in Art and in Sport: A Contribution to the Investigation of Aesthetics of Sport. Journal of the Philosophy of Sport, Champaing, n. 37, p. 182-193, 2010.

MASTERSON, Dan. Sport, theatre and art in performance. In: LENK, Hans (ed.). Topical problems of sport philosophy. Schorndorf: Karl Hofmann, 1983. p. 169-183.

MITIAS, Michael. "Can we speak of aesthetic experience?". In: MITIAS, Michael. (ed.). Possibility of Aesthetic Experience. Dordrecht: Martinus Nijhoft Publishers, 1986. p.47-58.

MODERNO, Ricardo. Estética do Futebol. Praxis da Educação Física e dos Desportos, Rio de Janeiro, v. 1, n. 2, p. 51-60, 1998.

NOGUEIRA, Ana Catarina; LACERDA, Teresa; CÔRTE-REAL, Alda. A estética no desporto de alto rendimento: um estudo realizado no ténis. In: CONGRESSO DE CIÊNCIAS DO DESPORTO E EDUCAÇÃO FÍSICA DOS PAÍSES DE LÍNGUA PORTUGUESA, 11, São Paulo, 2006. São Paulo: Renovação e Consolidação, 2006. 
PARRY, Jim. Sport, art and the aesthetics. Sport Science Review, Champaing, v. 12, p. 15-20, 1989.

PERNIOLA, Mario. A estética do século XX. Lisboa: Editorial Estampa, 1998.

PIETER, Willy; HEIJMANS, John. Scientific coaching for Olympic Taekwondo. 2. ed. Oxford: Meyer e Meyer Sport, 2000.

PIETER, Willy; ZEMPER, Eric. Cerebral Concussions in Taekwondo Athletes. In: HOERNER, Earl. Head and Neck Injuries in Sports. Philadelphia: American Society for Testing and Materials, 1994.

RAMIREZ, S. WTF Launches Global Membership System: Mas Taekwondo, 31 jan. 2011. Disponível em: <http://en.mastaekwondo.com/2011/01/wtf-launchesglobal-membership-system>. Acesso em: 24 fev. 2013.

SCHILLER, Friedrich. Cartas sobre a educação estética da humanidade. São Paulo: EPU, 1991.

STECKER, Robert. Aesthetic Experience and Aesthetic Value. Philosophy Compass, v. 1, n. 1, p. 1-10, 2006.

WRIGHT, Lesley. Aesthetic implicitness in sport and the role of aesthetic concepts. Journal of the Philosophy of Sport, Champaing, v. 30, p. 83-92, 2003.

WOJCIECH, Cynarski; KAZIMIERZ, Obody?ski. Corporeality in martial arts anthropology. Human Movement, Amsterdam, v. 12, n. 3, p. 291-297, 2011.

WORLD TAEKWONDO FEDERATION. Present Day Taekwondo. Korea: WTF. Disponível em: <http://www.wtf.org/wtf_eng/site/about_taekwondo/ present_day.html>. Acesso em: 24 fev. 2013.

Financiamento da pesquisa: FCT (Fundação para a Ciência e a Tecnologia, Portugal)

Endereço para correspondência:

Rebeca Cardozo Coelho

Rua Evaristo Lopes Guimarães, №14. Código Postal 3360-106,

Lorvão, Coimbra, Portugal.

E-mail: rebecacoelho@hotmail.com

Recebido em05.03.2013

Aprovado em: 20.04.2013

Movimento, Porto Alegre, v. 19, n. 03, p. 295-314, jul/set de 2013. 